\title{
山地区域土地生态红线划定方法与实证研究 以重庆市涪陵区义和镇为例
}

\author{
丁雨賝 ${ }^{1}$, 冯长春 ${ }^{*}$, 王利伟 ${ }^{2}$ \\ (1. 北京大学城市与环境学院, 北京 $100871 ; 2$. 清华大学建筑学院, 北京 100084)
}

\begin{abstract}
摘 要: 无序和不合理的土地利用是引发生态问题的重要因素。合理划定土地生态红线, 可协调土地利用和生态环 境的关系, 促进土地资源的合理配置, 保障区域生态安全。山地区域地势起伏较大, 水系密布, 土地利用破碎化, 作 为重要的水土保持和水源涵养区域, 是进行生态恢复和重建的关键地区。本文以山地区域村镇为例, 运用 GIS 平 台, 基于生态敏感性和生态服务价值, 对土地生态进行综合评价, 据此划定刚性和弹性的土地生态红线。生态敏感 性评价的指标包括坡度、植被覆盖度、水体、土壤类型和降水侵蚀力等 5 个指标; 生态服务价值评价的指标包括食 物生产、原料生产、气体调节、气候调节、水文调节、土壤保持、维持养分循环、生物多样性和美学景观 9 个指标。义 和镇的刚性生态红线内所包含的刚性生态保护区面积为 $43.90 \mathrm{~km}^{2}$, 占义和镇总面积的 $44.34 \%$ 。弹性生态红线包 含的弹性生态保护区面积为 $29.18 \mathrm{~km}^{2}$, 占义和镇总面积的 $29.47 \%$ 。义和镇的生态红线范围主要包含东北部山地 区域和南部水系丰富地区, 该区域的生态敏感性较高, 同时也有较高的生态服务价值, 因此生态红线的划定对于生 态修复和生态保护具有指引作用, 为生态系统健康发展提供基础保障, 并可为构建生态文明安全格局提供科学 支持。
\end{abstract}

关 键 词: 山地区域;土地生态红线; 生态敏感性;生态服务价值; 重庆市义和镇

\section{1 引言}

生态空间是一个蕴含时间、空间、自然资源、生 物多样性和生态服务功能的综合载体(李力等, 2014)。2015年国务院印发了《生态文明体制改革 总体方案》, 将生态文明建设放在了更突出的地 位。生态红线作为生态文明建设的重要条件, 识别 生态红线, 构建生态红线划分的方法体系, 对于保 障国土安全、生态环境安全、资源安全具有重要 意义。

生态保护红线是指依法在重点生态功能区、生 态环境敏感区和脆弱区等区域划定的严格管控边 界, 是国家和区域生态安全的底线。土地生态红线 内的生态用地承载了多种生态功能, 提供了调节气
候、保持水土等重要生态价值。红线明确了禁止建 设区的范围, 也给出了土地开发的空间范围和边 界, 可良好地协调国土开发和生态环境容量, 提高 资源的综合承载力(马永欢等, 2014)。随着生态环 境的恢复、环境污染的治理和耕地质量的提高, 生 态红线的划定可进一步为粮食和食品安全提供有 力保障。生态红线同时也界定了土地开发边界, 而 土地开发边界的划定可提高建设用地利用效率, 降 低在经济发展中不必要的土地浪费, 为科学构建土 地储备制度, 促进良性互动的土地市场提供依据 (冯长春, 2008)。因此, 土地生态红线的划定不仅是 实现国土安全的重要保障, 也是实现土地可持续利 用的前提条件。

学界对于生态红线的划定方法已进行了一定

收稿日期: 2015-02;修订日期: 2015-04。

基金项目: 国家科技支撑计划项目(2012BAJ22B04) [Foundation: National Science and Technology Support Program of China, No.2012BAJ22B04]。

作者简介:丁雨賝(1990-),女,河南洛阳人,硕士研究生,主要研究方向为土地利用规划,E-mail: dingyuchen@pku.edu.cn。 通讯作者:冯长春(1957-), 男, 教授,博士生导师, 主要研究方向为城市规划与土地利用,E-mail: fcc@pku.edu.cn。 
的探索。如许妍等(2013)根据湿地面积、生物资源 量等指标对渤海进行了生态红线划定; 王云才等 (2015)结合生态网络规划对平原地区一一安徽省宣 城市南渏湖地区进行了生态红线划定; 燕守广等 (2014)基于生态功能对江苏省生态红线区域划定进 行了研究。综合来看, 目前对于生态红线划定的研 究和实践多集中在生态影响因素方面, 涉及土地利 用的评价不多, 关于土地生态红线划定的研究也 较少。

由于山地区域以山地地形为主, 自然环境恶 劣, 对生产生活建设限制明显, 生态问题凸显, 也是 生产建设与自然环境冲突较大的地区, 因此山地区 域具有土地利用类型多样、生态敏感性强和生态服 务价值多样的特征, 是生态文明建设的重要空间单 元。山地区域的主要生态功能为保持水土和水源 涵养, 生态脆弱性主要表现在水土流失和土壤侵蚀 等方面。山地区域生态红线的划定,需要兼顾山区 特有生态脆弱区和山区特有的生态功能。因而, 山 地区域生态红线的研究对于山区生态文明建设、协 调生态与经济可持续发展有着重要的理论意义和 实践价值。在具体方法上, 研究生态环境综合评价 的方法很多, 生态敏感性评价是常用的评价方法之 一。例如, 冯长春等(2014)运用生态敏感性评价来 确定生态保育尺度; 李广娣等(2013)基于生态敏感 性划分了平原地区铜陵市的生态保育尺度。生态 服务价值也是生态环境综合评价的重要组成部 分。例如傅伯杰等(2001)将生态系统服务功能评价 纳人生态综合评价的框架内; 李双成等(2014)认为 生态系统服务对于保障生态安全和社会经济可持 续发展有重要的作用。因此, 本文在总结前人研究 的基础上, 基于生态敏感性评价和生态服务价值评 价, 以重庆市涪陵区义和镇为例, 针对山地区域进 行土地生态红线划定方法研究, 旨在建立一套系统 综合的生态现状评价和生态红线划定体系, 以期提 供一种对山地区域土地的生态保护和生态建设提 的技术方法和思路。

\section{2 土地生态红线划定方法模型构建}

\section{1 总体技术框架}

土地生态红线的划定, 是为了解决土地利用与 资源环境的冲突问题, 以达到土地利用和自然生态 关系的协调发展。不合理的土地利用和生产建设
会造成自然生态系统的严重破坏,因此土地生态红 线需要为生态保护提出一种合理的土地利用空间 布局和解决办法。同时土地生命系统不仅是一个 自然的综合系统, 也为人类的社会经济系统提供包 括食物生产、旱涝调节、旅游审美等生态服务功能 (Daily, 1997)。因此, 在土地生态红线划定过程中 需要综合考虑自然系统和生态服务系统 2 个方面。

本文从生态敏感性评价和生态服务价值 2 个方 面,构建山地区域土地生态红线划定方案(图 1)。生 态敏感性指生态系统对人类活动干扰和自然环境 变化的反应程度(欧阳志云等, 2000)。生态敏感性 评价是指在现有自然环境背景下, 人类活动干扰和 自然环境变化导致发生区域生态或环境问题的难 易程度及其可能性大小, 也就是生态环境问题出现 的概率大小(杨志峰等, 2002; 禹莎等, 2008; 颜磊 等, 2009)。生态敏感性评价的实质是对现状自然 环境下, 潜在的生态问题进行明确辨识, 并将其落 实到具体空间区域的过程(徐广才等, 2007)。生态 敏感性高的区域, 容易发生自然灾害, 生态系统比 较脆弱, 容易受损, 应减少人类活动, 主要以生态恢 复重建为主。生态敏感性是反映生态环境现状的 重要指标, 是划定土地生态红线的重要依据。

另一方面, 生态系统可为人类提供产品以及直 接和间接的服务是生态功能的重要体现。生态系 统服务是指通过生态系统的结构、过程和功能直接 或间接地得到的生命支持产品和服务, 自然资产含 有多种与其生态服务功能相应的价值(Repetto, 1992; Costanza et al, 1997)。随着全球范围内的城 市化、工业化的发展,生态系统服务的稀缺性越发 增强。尤其在中国农村地区, 对于关键资源的过度 开发, 导致生态系统服务严重退化, 对生态安全造 成了严重威胁。通过对生态服务价值进行评价, 可

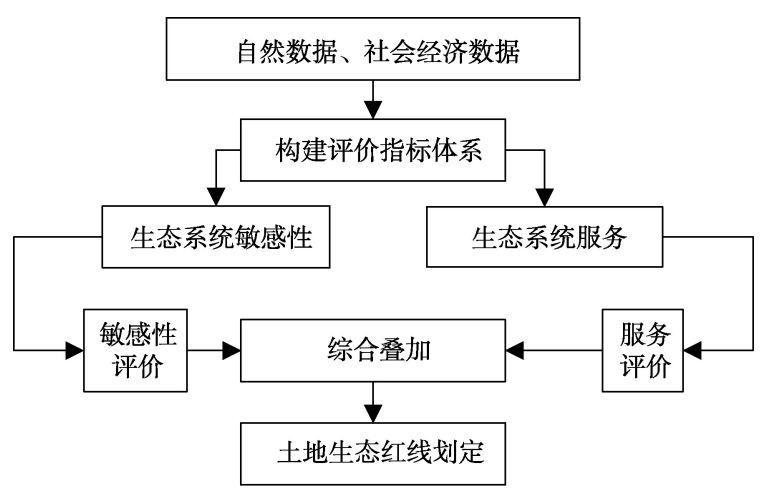

图 1 土地生态红线划定技术框架

Fig.1 Framework for determining ecological red line 
以根据生态服务价值对区域进行功能划分, 为生态 红线划定提供支持, 同时可以提升生态服务功能, 推动生态修复工作。因此本文在生态敏感性和生 态服务价值两部分评价的基础上, 进行生态红线划 定,基本思路为: (1)建立生态敏感性评价指标体系, 通过土地利用现状调查数据和 ArcGIS 软件, 对研 究区域土地利用的生态敏感性进行评价, 评价单元 的生态敏感性评价总分等于各单因子评分值加权 求和结果, 即:

$$
P_{1}=\sum_{i=1}^{i=n} F_{i} W_{i}
$$

式中: $P_{1}$ 为某土地评价单元生态敏感性评价总分 值; $W_{i}$ 为第 $i(i=1,2,3, \ldots \ldots, n)$ 个因子的权重值; $F_{i}$ 为 第 $i$ 个因子的生态敏感性评价分值, 根据生态敏感 性评价结果对区域进行生态敏感性分等定级; (2)建 立生态服务价值评价指标体系, 通过对山地区域生 态服务价值类型的研究, 对不同地类不同类型的生 态服务价值进行评价 (标准化后结果记为 $P_{2}$ ), 根据 评价结果对区域进行生态服务价值分等定级; (3) 将 生态敏感性评价结果和生态服务价值评价结果进 行综合评价, 运用布尔运算将生态敏感性评价结果 和生态服务价值评价结果分级叠加; (4)根据不同生 态保护尺度得到土地生态红线刚性约束界限值和 弹性约束界限值。

\section{2 生态敏感性评价指标构建}

由于村镇区域图件规格不统一, 基础数据缺失 较多, 且生态敏感性具有复杂性和综合性, 因此, 根 据义和镇山地区域水土流失较为严重的现状和西 南地区水源涵养较丰富的特点, 结合环境主导因 素,进行评价指标选择。

\section{(1) 坡度}

西南地区处于中国青藏高原向四川盆地的过 渡地带, 由于特殊的地质地貌因素, 地震、滑坡和土 壤侵蚀是该地区经常发生的灾害。在小尺度研究 中, 坡度是主要指标。研究表明, 坡度越陡, 汇流的 时间越短, 径流能量越大, 对坡面的冲刷就越强烈, 侵蚀量就越大。在坡度较陡的条件下, 土壤侵蚀率 和滑坡发生率随着坡长的增加而迅速增加。对于 耕作来说, 坡度 $25^{\circ}$ 以上的地区已不太适宜。但西 南山区, $25^{\circ}$ 以上的地区分布较广。因此坡度是影 响生态敏感性的重要因素之一。本文采用了 $<2^{\circ}$ 、
$2 \sim 6^{\circ} 、 6^{\circ} \sim 15^{\circ} 、 15^{\circ} \sim 25^{\circ} 、>25^{\circ}$ 等 5 个分级, 分别对应 平坡、缓坡、中坡、陡坡、急坡, 即一般敏感性、轻度 敏感性、中度敏感性、高度敏感性和极敏感性。

(2) 植被覆盖度

陆地植被是联系土壤、陆地水体和大气之间的 媒介体, 可促进物质交换和能量交换。植被覆盖度 作为一个直接量化的指标, 可很大程度上反映一个 地区的植被情况，进而反映一个地区的生态条件。 西南地区山地是重要的水土保持区, 将植被覆盖度 纳人评价指标, 可较好地评价生态敏感特征。根据 植被覆盖度普遍分级， $\leqslant 20 \%$ 为极低覆盖度，20\% $40 \%$ 为低覆盖度, $40 \% \sim 60 \%$ 为中覆盖度, $60 \%$ $80 \%$ 为高覆盖度, $>80 \%$ 为极高覆盖度, 可根据这个分 级对植被覆盖度进行评价和分级(陈效述, 2009), 分 别对应一般敏感性、轻度敏感性、中度敏感性、高度 敏感性和极敏感性。

\section{(3) 水体}

水体是对生态环境的水热交换有着重要影响 的因素。义和镇坑塘水面较多,需要把水体纳人评 价体系。根据已有学者(潘竟虎等, 2006; 苒圣宏 等, 2009)对水体资源的研究,往往依据距离水体远 近划分水体因子敏感性级别, 具体划分等级见表 1 。

\section{(4) 土壤类型}

不同土壤类型反映了不同程度的土壤侵蚀敏 感性,对于土壤侵蚀的形成和分异规律有着显著影 响, 并且可在一定程度上反映水土流失情况(刘春 霞等, 2011), 对于西南地区山地尤其重要。因此根 据不同土壤类型可以划分不同的生态敏感性(表 1)。

(5) 降水侵蚀力

降雨是引起水土流失的重要原因, 主要是由于 降水的动能对于土粒产生冲击, 同时降雨产生的径 流进一步加剧水土流失。王万中(1996)等通过对全 国 125 个重点站降水资料的分析,得出了各站年降 水量和降雨侵蚀力 $R$ 值, $R$ 值是一个表征降雨量、降 雨强度、降雨厉时、雨滴大小及下降素的指标。该 指标已经被国内多个相关研究参考引用(凡非得 等, 2011)。本文在王万中基础上,通过空间差值得 到义和镇降雨侵蚀力 $R$ 值空间分布情况 ${ }^{\circledR}$, 按表 1 进 行分级。

\section{3 生态服务价值评价指标构建}

近年来, 国内外学者对生态系统服务价值进行

(1)由于单因子指标图太多, 生态敏感性和生态服务价值一共有 14 个单因子评价图, 全部放进文章比较冗余, 因此文中只放了 综合评价的分级表和结果图。 
表 1 生态环境敏感性评价因子及分级

Tab.1 Indicators of ecological sensitivity assessment and classification in Yihe Town, Chongqing Municipality

\begin{tabular}{ccccccc}
\hline 生态敏感性因子 & 权重 & 一般敏感 & 轻度敏感 & 中度敏感 & 高度敏感 & 极敏感 \\
\hline 坡度 $/{ }^{\circ}$ & 0.25 & $\leqslant 2$ & $2 \sim 6$ & $6 \sim 15$ & $15 \sim 25$ & $>25$ \\
植被覆盖度 $/ \%$ & 0.25 & $\leqslant 20$ & $20 \sim 40$ & $40 \sim 60$ & $60 \sim 80$ & $>80$ \\
水体 $/ \mathrm{m}$ & 0.15 & $\geqslant 500$ & $350 \sim 500$ & $200 \sim 350$ & $100 \sim 200$ & $<100$ \\
土壤类型 & 0.15 & 水稻土 & 新积土、山地草甸土 棕壤、黄褐土、石灰(岩)土 黄壤、黄棕壤、粗骨土 & 紫色土 \\
$\begin{array}{c}\text { 降雨侵蚀力 } R \text { 值/ } \\
\left(\mathrm{MJ} \cdot \mathrm{mm} \cdot \mathrm{hm}^{-2} \cdot \mathrm{h}^{-1} \cdot \mathrm{a}^{-1}\right)\end{array}$ & 0.20 & $\leqslant 250$ & $250 \sim 300$ & $300 \sim 350$ & $350 \sim 400$ & $>400$ \\
\hline
\end{tabular}

了许多研究。对于生态服务价值的评估方法有 2 种, 分别为基于单位生态服务产品价格的方法(吴 钢等, 2001; 赵同谦等, 2004; 王兵等, 2009)和基于 单位面积价值当量因子的方法 (谢高地等, 2001; 李 正等, 2012)。前者对数据需求高、计算复杂、难以 形成统一评价标准和广泛应用, 对于村镇地区来 说, 所需数据比较难以获得; 而后者设定的单位生 态系统是提供生态服务产品的标准功能单元, 尽管 相对简单, 但易于广泛应用(谢高地等, 2015), 对于 村镇地区来说, 选用这种方法比较适宜。

根据 Costanza 等(1997)、谢高地等(2015)的研 究, 同时参考其他国内学者的研究成果(李正等, 2012), 以生态服务价值当量因子法为基础, 考虑区 域差异性,对该标准进行修正和补充。山地区域村 镇的生态系统以第一产业为主, 结合乡村社会经济 对生态系统服务的需求, 选取食物生产、原料生产、 气体调节、气候调节、水文调节、土壤保持、维持养 分循环、生物多样性和美学景观等 9 个类别的生态 系统服务作为评价指标。据此得到义和镇各类生 态系统提供的生态服务价值。对各类生态服务价 值加总后进行标准化, 在 ArcGIS 10.2 中给不同地 类输人其相应的生态服务价值分值 (记为 $P_{2}$ ), 即可 完成生态服务价值评价。

\section{3 土地生态红线划定的实证研究}

\section{1 研究区概况}

研究区义和镇位于重庆市区东北部(图 2), 涪陵 市域西部长江北岸, 镇域面积 $99.45 \mathrm{~km}^{2}$, 长江从义 和镇西面、南面呈 “L”型流过, 属沿江浅丘地带。研 究区地势东高西低,系由北向南倾斜的长江河谷浅 丘福皱地带, 海拔高度多在 160 700 m, 地貌以低 山、沟谷、平坝夹溪沟为主, 形成低山丘陵、河谷浅 丘、河漫滩阶地 3 种地貌。由于处在中国地势第一

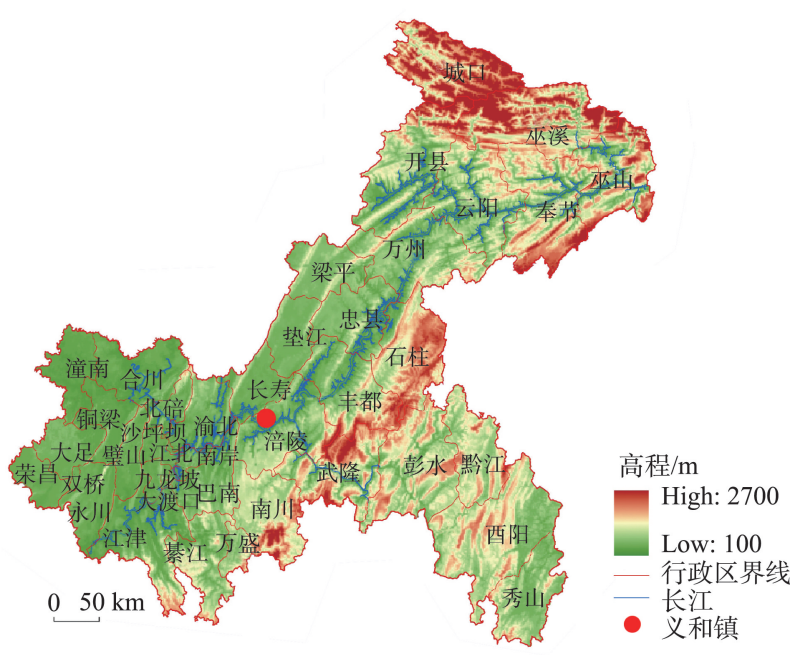

图 2 义和镇区位图

Fig.2 Location of Yihe Town, Chongqing Municipality

阶梯和第二阶梯过渡区域,受地形和水系影响, 滑 坡泥石流频发, 水土流失严重, 是生态环境高度脆 弱的地区。总体来看,农村居民点在山地、丘陵地 区广泛分布,呈现“大分散、小集中”的格局,不仅不 利于经济建设,对生态环境也造成了一定的压力和 破坏。与此同时,随着城镇化的加速发展,资源整 合、旅游生态资源统筹开发的需求意愿加强,生态 保护和生态恢复成为镇域统筹规划的前提和重点。

\section{2 数据来源}

本文采用的数据主要包括: 义和镇第二次全国 土地调查的土地利用现状调查数据、精度为 $5 \mathrm{~m}$ 的 义和镇数字高程模型(DEM)和义和镇行政区划图, 以及从联合国粮农组织(FAO)和维也纳国际应用系 统研究所(IIASA)所构建的世界土壤数据库(Harmonized World Soil Database version 1.1)(HWSD)中提 取的精度为 $1 \mathrm{~km}$ 的中国土壤类型格网数据, 所有数 据均在 ArcGIS 10.2 的平台上运行和处理。

\section{3 生态敏感性评价}

根据研究区域实际情况,结合生态敏感性评价 
较为成熟的方法(潘竟虎等, 2006; 潘峰等, 2011; 许 妍等, 2013), 建立评价指标体系, 对义和镇进行生 态敏感性评价。具体方法是将义和镇划分为 $50 \mathrm{~m} \times$ $50 \mathrm{~m}$ 的网格, 首先进行单因子评价。在 ArcGIS 10.2 中提取每个网格的单因子值, 按照对环境敏感 的程度, 将其划分为一般敏感性、轻度敏感性、中度 敏感性、高度敏感性和极敏感性, 分别赋值 $1 、 3 、 5$ 、 7、9。各因子权重根据层次分析法(AHP)获得。通 过对义和镇自然生态条件及周围的环境条件等各 方面情况的综合调查, 查阅相关资料并与专家交 流, 反复论证。将评价因子进行定量化处理, 其分 级结果见表 1 。

在第一个步骤提取单因子值的基础上, 进行多 因子综合评价。义和镇镇域内敏感性得分范围为 1.03 7.60。在ArcGIS 10.2 中, 为识别敏感性边界, 对敏感性得分进行重新分类, 分为一般敏感、轻度 敏感、中度敏感、高度敏感、极敏感等 5 类, 得到生态 敏感性评价图(图 3), 分类标准及各类敏感性面积见 表 2。从表 2 可以看出, 义和镇生态一般敏感的土 地面积只占全区 $11.58 \%$, 而高度敏感和极敏感的地 区占到 $32.69 \%$ 。从空间分布上来看, 高度敏感和极 敏感地区主要分布在北部山地地区及南部沿长江 地带, 该地区坡度较大, 水土流失严重, 加上人类活 动具有 “小聚集、大分散”的态势, 因此对全区的生 态环境造成了明显的压力和影响。生态敏感性不 高的地区主要集中在镇域中部, 具有良好的生产生 活条件, 海拔较低, 是人们生产生活主要集中区。

\section{4 生态服务价值评价}

根据生态服务价值当量因子的方法, 义和镇的 食物生产、原料生产等 9 个生态服务类型进行价值 核算, 具体核算结果见表 3 。将各地类的生态服务 价值加总, 并且标准化为 0 100 之间, 对不同生态服 务价值的地类进行重新分类为: 极低生态服务价 值、低生态服务价值、一般生态服务价值、高生态服 务价值和极高生态服务价值, 得到生态服务价值结 果图结果(表4)。结合图 4 和表 4 可以看出, 生态服 务价值较高的主要在山地、水系、湿地、园林地等区 域, 总体来说, 义和镇土地生态服务价值总体处于 中等水平, 高生态服务价值区占镇域面积 $23.92 \%$, 该区集中分布在北部地区, 极高生态价值区占全区 面积的 $14.21 \%$, 该区除了长江沿岸地区以外, 零星 分布在镇域范围内。一般生态服务价值、低生态服 务价值和极低生态服务价值基本上平均分布在全
镇范围内。低生态服务价值区面积,一般生态服务 价值区面积和高生态服务价值区面积基本相同, 都 远高于极低生态服务价值区面积和极高生态服务 价值区面积。从极低生态服务价值到极高生态服 务价值, 5 类面积大小分布呈现纺锤状。

\section{5 生态红线划定}

生态红线的划定是在综合考虑生态敏感性分 析、生态服务价值评价基础上,运用布尔运算法将 生态敏感区和生态服务价值高的地区进行叠加, 只 要在所选定的生态敏感区或者生态服务价值区内, 直接划定为生态红线范围。

由于山地区域土地利用破碎化现象严重, 因此 生态评价结果也呈现出图斑严重破碎化现象。为 科学合理的划定生态红线范围, 对数据结果进行处 理,参考中华人民共和国环境保护部颁布的《生态 保护红线划定技术指南》, 结合村镇区域尺度, 进行 生态红线范围的数据处理和图形整饰。首先, 进行

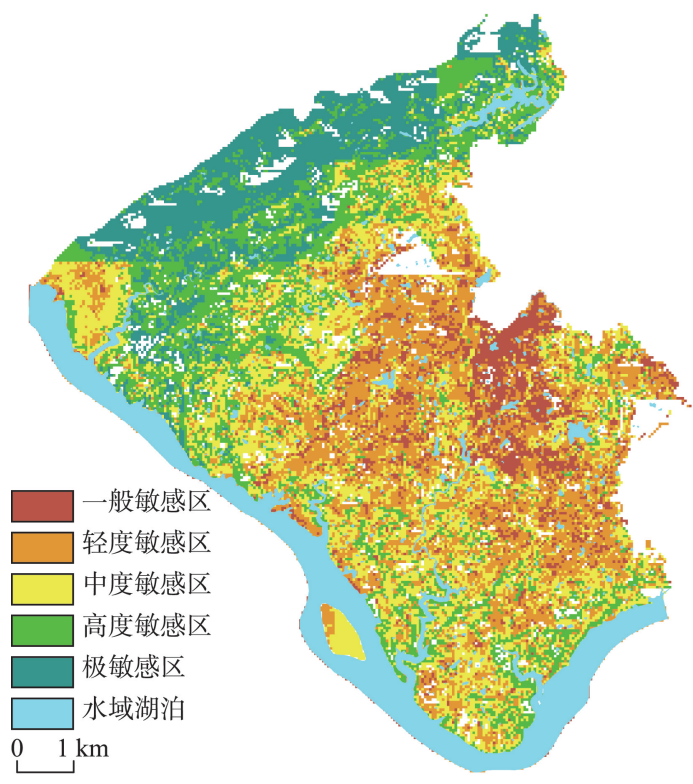

图 3 涪陵区义和镇生态敏感性评价图

Fig.3 Spatial distribution of ecological sensitivity classes in Yihe Town, Chongqing Municipality

\section{表 2 生态敏感性分级赋值表}

Tab.2 Ecological sensitivity classes in Yihe Town, Chongqing Municipality

\begin{tabular}{cccccc}
\hline 生态敏感性 & 一般敏感 轻度敏感 中度敏感 & 高度敏感 & 极敏感 \\
\hline 敏感性总分 & $(1,3]$ & $(3,4]$ & $(4,5]$ & $(5,6]$ & $(6,7.6]$ \\
面积 $/ \mathrm{km}^{2}$ & 10.755 & 27.245 & 24.495 & 18.693 & 11.665 \\
百分比 $/ \%$ & 11.58 & 29.34 & 26.38 & 20.13 & 12.56 \\
\hline
\end{tabular}


表 3 义和镇不同土地利用类型单位面积生态服务价值 $/\left(\right.$ 元 $\left.\cdot \mathbf{h m}^{-2} \cdot \mathbf{a}^{-1}\right)$

Tab.3 Values of ecosystem services per unit area of different land use types in Yihe Town, Chongqing Municipality/(yuan $\left.\cdot \mathbf{h m}^{-2} \cdot \mathbf{a}^{-1}\right)$

\begin{tabular}{|c|c|c|c|c|c|c|c|c|c|c|}
\hline \multirow[b]{2}{*}{ 生态系统分类 } & \multicolumn{2}{|c|}{ 供给服务 } & \multicolumn{3}{|c|}{ 调节服务 } & \multicolumn{3}{|c|}{ 支持服务 } & \multirow{2}{*}{$\begin{array}{l}\text { 文化服务 } \\
\text { 美学景观 }\end{array}$} & \multirow{2}{*}{ 总和 } \\
\hline & 食物生产 & 原料生产 & 气体调节 & 气候调节 & 水文调节 & 土壤保持 & 维持养分循环 & 生物多样性 & & \\
\hline 农田 & 507.82 & 112.59 & 409.01 & 213.70 & 687.05 & 238.97 & 71.23 & 78.13 & 34.47 & 2352.97 \\
\hline 林地 & 137.87 & 314.80 & 1038.62 & 3108.96 & 1895.71 & 1266.10 & 96.51 & 1151.21 & 505.52 & 9515.30 \\
\hline 草地 & 174.63 & 257.36 & 905.34 & 2394.34 & 1755.54 & 1102.96 & 82.72 & 1001.85 & 441.18 & 8115.92 \\
\hline 湿地 & 234.38 & 229.78 & 873.17 & 1654.43 & 11135.27 & 1061.60 & 82.72 & 3616.78 & 2173.74 & 21061.88 \\
\hline 荒漠 & 0.00 & 0.00 & 9.19 & 0.00 & 13.79 & 9.19 & 0.00 & 9.19 & 4.60 & 45.96 \\
\hline 水域 & 367.65 & 105.70 & 353.87 & 1052.40 & 46985.95 & 427.40 & 32.17 & 1171.89 & 868.58 & 51365.61 \\
\hline 城镇用地 & - & - & - & - & - & - & - & - & 165.20 & 165.20 \\
\hline
\end{tabular}

表 4 生态服务价值评价表

Tab.4 Ecosystem services value classes in Yihe Town, Chongqing Municipality

\begin{tabular}{cccccc}
\hline 生态服务价值 & 极低价值 & 低价值 & 一般价值 & 高价值 & 极高价值 \\
\hline 服务价值评分 & $(0,0.11]$ & $(0.11,3.93]$ & $(3.93,6.61]$ & $(6.61,22.66]$ & $(22.66,100]$ \\
面积 $/ \mathrm{km}^{2}$ & 8.57 & 26.80 & 25.89 & 23.68 & 14.07 \\
百分比 $/ \%$ & 8.66 & 27.07 & 26.15 & 23.92 & 14.21 \\
\hline
\end{tabular}

数据聚合, 在 ArcGIS 10.2 中, 通过聚合工具将叠加 结果中相对聚集或邻近的图斑聚合为相对完整连 片的图斑。考虑到前期评价单元网格大小和村镇 范围较小两方面因素, 选择聚合距离为 $50 \mathrm{~m}$, 最小 孔洞面积为 $3 \mathrm{~km}^{2}$; 其次, 将破碎图斑剔除。选择剔 除破碎图斑的阈值为 $5 \mathrm{~km}^{2}$, 面积在 $5 \mathrm{~km}^{2}$ 以下的图 斑删除, 以减少红线区的破碎化程度, 但同时又保 留重要的水源涵养和水土保持区域。最后, 根据实
际土地利用类型和影像地物分布进行遥感判读与 补充勾绘,扣除聚合后图斑内的大型建设用地和集 中连片农田,调整生态保护红线界线,形成边界清 晰、切合实际、生态完整性好的生态红线分布图。

具体操作中将生态敏感性极敏感区、高度敏感 区与极高、高生态服务价值区进行叠加, 得到刚性 生态红线,刚性生态红线是建设发展不可逾越的边 界, 红线内应以生态保护和生态恢复为主(图 5)。义

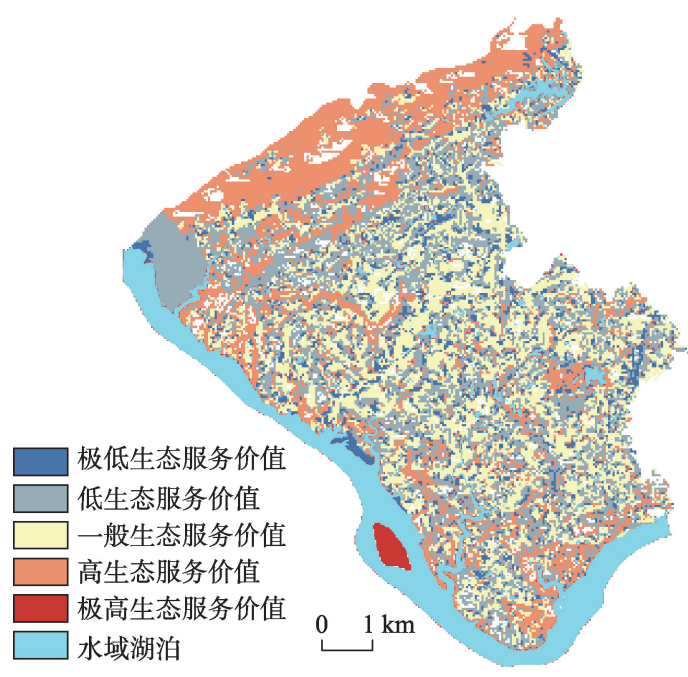

图 4 义和镇生态服务价值评价图

Fig.4 Spatial distribution of ecosystem services value classes in Yihe Town, Chongqing Municipality

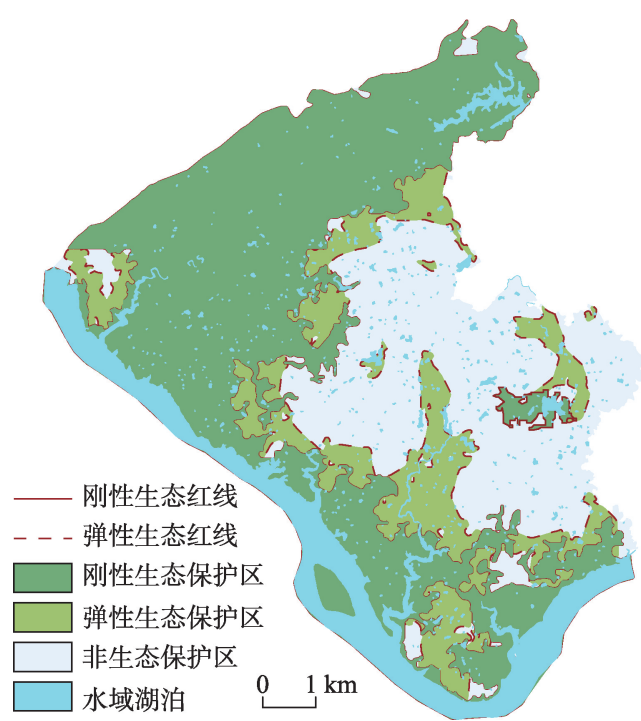

图 5 义和镇生态红线划定结果

Fig.5 Ecological red line zones in Yihe Town, Chongqing Municipality 
和镇刚性生态红线所包含的区域为刚性生态保护 区, 面积为 $43.90 \mathrm{~km}^{2}$, 占镇域面积 $44.34 \%$, 范围主 要包括镇域的东部、北部和长江沿岸, 主要起重点 防御水土流失和水源涵养作用,生态红线的划定为 义和镇的规划建设、生态保护提供了控制性基准。

与刚性生态红线不同, 弹性生态红线可根据镇 域的发展阶段以及生态环境保护状况和生产建设 规模划定生态保护边界。随着生态恢复和镇域发 展的需要可发生变化, 但是刚性边界是弹性边界坚 守的底线。义和镇的弹性生态红线是中生态敏感 区与一般生态服务价值区相叠合的结果(图 5)。与 刚性生态保护区相比, 弹性生态红线主要分布在义 和镇南部地区, 所包围的弹性生态保护区面积为 $29.18 \mathrm{~km}^{2}$, 占义和镇镇域面积的 $29.47 \%$; 义和镇南 部地区虽然总体海拔没有北部山区高, 但是有丰富 的河网水系, 生态敏感性和生态服务价值都处在中 等位置。划定弹性土地生态红线, 可对土地利用和 生态保护进行阶段性指导, 根据镇域的发展状况可 以进行弹性调整, 这样既可以保护生态环境又不阻 碍镇域的整体发展。

\section{4 结论与讨论}

经过 30 多年的高速城镇化进程后, 中国生态环 境问题愈发突出, 大力推进生态文明建设、构建人 与自然和谐发展的现代化新格局是国家重大战略 方针。本文以山地区域村镇为案例, 基于生态系统 的综合评价, 探讨了生态红线的划定技术, 从生态 敏感性、生态服务价值 2 个方面, 系统综合地对山地 区域村镇生态红线划定方法进行了探索, 建立了一 套划定村镇生态红线的技术流程和方法, 对以基础 空间单元构建生态安全格局具有重要的理论意义 和实践价值。

义和镇的刚性生态红线区主要分布在北部山 地区域和南部沿长江沿岸地区, 弹性生态红线与刚 性生态红线相比地域范围有所扩大, 包括了南部一 些地区。由于义和镇北部山地区域有比较重的水 土流失问题, 生态环境较为敏感, 是生态系统容易 遭受破坏的区域。但北部地区植被丰富, 生态服务 价值高; 南部地区水系丰富, 也蕴含了较高的生态 服务功能, 对于增强生物多样性和水源涵养有重要 作用。因此, 生态红线区的划定, 可较合理地保护 生态脆弱地区和生态服务价值较高的地区, 以便科
学引导区域生产建设规划,保障生态系统向健康方 向发展。

山地区域村镇多位于中国西南地区, 河流水系 发达、生态环境脆弱, 属于典型的生态敏感性高、生 态价值高的地区, 因而生态红线划定复杂、生态保 护区所占面积较大。从预防自然灾害、减少生产安 全风险、促进经济活动合理分布的角度来看, 山地 区域村镇应以防范自然灾害、恢复生态环境为主要 目标, 结合国家生态补偿转移支付政策, 有序地引 导位于生态敏感区的居民外迁, 构建村镇生态保护 机制, 促进村镇人地和谐发展。

\section{参考文献(References)}

陈效述, 王恒. 2009. 1982-2003 年内蒙古植被带和植被覆盖 度的时空变化 [J]. 地理学报, 64(1): 84-94. [Chen X Q, Wang H. 2009. Spatial and temporal variations of vegetation belts and vegetation cover degrees in Inner Mongolia from 1982 to 2003[J]. Acta Geographica Sinica, 64(1): 84-94.]

凡非得, 王克林, 宣勇, 等. 2011. 西南喀斯特区域生态环境 敏感性评价及其空间分布 $[\mathrm{J}]$. 长江流域资源与环境, 20 (11): 1394-1399. [Fan F D, Wang K L, Xuan Y, et al. 2011. Eco-environmental sensitivity and its spatial distribution in karst regions, Southwest China[J]. Resources and Environment in the Yangtze Basin, 20(11): 13941399.]

冯长春. 2008. 中国土地储备制度探讨 [J]. 农业工程学报, 24 (S1): 247-249. [Feng C C. 2008. Research on the land reserve system of China[J]. Transactions of the Chinese Society of Agricultural Engineering, 24(S1): 247-249.]

冯长春, 曹敏政, 谢婷婷. 2014. 不同生态保育尺度下铜陵市 土地利用结构优化 [J]. 地理研究, 33(12): 2217-2227.

[Feng C C, Cao M Z, Xie T T. 2014. Optimization of land use structure in Tongling City based on different ecological conservation scales[J]. Geographical Research, 33 (12): 2217-2227.]

傅伯杰, 刘世梁, 马克明. 2001. 生态系统综合评价的内容与 方法 [J]. 生态学报, 21(11): 1885-1892. [Fu B J, Liu S L, Ma K M. 2001. The contents and methods of integrated ecosystem assessment[J]. Acta Ecologica Sinica, 21(11): 1885-1892.]

李广娣, 冯长春, 曹敏政. 2013. 基于土地生态敏感性评价的 城市空间增长策略研究: 以铜陵市为例 [J]. 城市发展研 究, 20(11): 69-74. [Li G D, Feng C C, Cao M Z. 2013. Study of urban spatial growth strategy based on ecological sensitivity assessment: A case study of Tongling[J]. Urban Development Studies, 20(11): 69-74.] 
李力, 王景福. 2014. 生态红线制度建设的理论和实践 $[\mathrm{J}]$. 生 态经济, 30(8): 138-140. [Li L, Wang J F. 2014. Institutional construction of ecological red line: Theory and practice[J]. Ecological Economy, 30(8): 138-140.]

李双成, 王珃, 朱文博, 等. 2014. 基于空间与区域视角的生 态系统服务地理学框架 [J]. 地理学报, 69(11): 16281639. [Li S C, Wang J, Zhu W B, et al. 2014. Research framework of ecosystem services geography from spatial and regional perspectives[J]. Acta Geographica Sinica, 69 (11): 1628-1639.]

李正, 王军, 白中科, 等. 2012. 贵州省土地利用及其生态系 统服务价值与灰色预测 [J]. 地理科学进展, 31(5): 577583. [Li Z, Wang J, Bai Z K, et al. 2012. Land use and ecosystem service values and their grey forecast in Guizhou Province[J]. Progress in Geography, 31(5): 577583.]

刘春霞, 李月臣, 杨华, 等. 2011. 三峡库区重庆段生态与环 境敏感性综合评价 [J]. 地理学报, 66(5): 631-642. [Liu C X, Li Y C, Yang H, et al. 2011. RS and GIS-based assessment for eco-environmental sensitivity of the Three Gorges Reservoir Area of Chongqing[J]. Acta Geographica Sinica, 66(5): 631-642.]

马永欢, 张丽君, 黄先栋. 2014. 确立我国土地管理红线的战 略思考 [J]. 中国软科学, (1): 29-35. [Ma Y H, Zhang L J, Huang X D. 2014. The strategic thinking on establishing red lines of land management[J]. China Soft Science, (1): 29-35.]

欧阳志云, 王效科, 苗鸿. 2000. 中国生态环境敏感性及其区 域差异规律研究 [J]. 生态学报, 20(1): 9-12. [Ouyang Z Y, Wang X K, Miao H. 2000. China's eco-environmental sensitivity and it's spatial heterogeneity[J]. Acta Ecologica Sinica, 20(1): 9-12.]

潘峰, 田长彦, 邵峰, 等. 2011. 新疆克拉玛依市生态敏感性 研究 [J]. 地理学报, 66(11): 1497-1507. [Pan F, Tian C Y, Shao F, et al. 2011. Evaluation of ecological sensitivity in Karamay, Xinjiang, Northwest China[J]. Acta Geographica Sinica, 66(11): 1497-1507.]

潘竟虎, 董晓峰. 2006. 基于 GIS 的黑河流域生态环境敏感性 评价与分区 $[\mathrm{J}]$. 自然资源学报, 21(2): 267-273. [Pan J H, Dong X F. 2006. GIS-based assessment and division on eco-environmental sensitivity in the Heihe River Basin [J]. Journal of Natural Resources, 21(2): 267-273.]

再圣宏, 宋晓龙, 李晓文, 等. 2009. 衡水湖国家自然保护区 生态敏感性分析 [J]. 地域研究与开发, 28(4): 129-133. [Ran S H, Song X L, Li X W, et al. 2009. The ecological sensitivity analysis in Heng-shui Lake National Nature Reserve[J]. Areal Research and Development, 28(4): 129133.]

王兵, 鲁绍伟. 2009. 中国经济林生态系统服务价值评估[J].
应用生态学报, 20(2): 417-425. [Wang B, Lu S W. 2009. Evaluation of economic forest ecosystem services in China[J]. Chinese Journal of Applied Ecology, 20(2): 417425.]

王万中, 焦菊英, 郝小品, 等. 1996. 中国降雨侵蚀力 $R$ 值的计 算与分布 $($ II $)[\mathrm{J}]$. 土壤侵蚀与水土保持学报, 2(1): 2939. [Wang W Z, Jiao J Y, Hao X P, et al. 1996. Distribution of rainfall erosivity $\mathrm{R}$ value in China[J]. Journal of Soil Erosion and Soil Conservation, 2(1): 29-39.]

王云才, 吕东, 彭震伟, 等. 2015. 基于生态网络规划的生态 红线划定研究: 以安徽省宣城市南渏湖地区为例 $[\mathrm{J}]$. 城 市规划学刊, (3): 28-35. [Wang Y C, Lv D, Peng Z W, et al. 2015. The demarcation of ecological red line based on ecological network planning: A case study of Nanyi Lake region in Anhui Province[J]. Urban Planning Forum, (3): 28-35.]

吴钢, 肖寒, 赵景柱, 等. 2001. 长白山森林生态系统服务功 能 [J]. 中国科学: 生命科学, 31(5): 471-480. [Wu G, Xiao H, Zhao J Z, et al. 2002. Forest ecosystem services of Changbai mountain in China[J]. Science in China: Life Sciences, 45(1): 21-32.]

谢高地, 鲁春霞, 成升鬼. 2001. 全球生态系统服务价值评估 研究进展 $[\mathrm{J}$ ]. 资源科学, 23(6): 5-9. [Xie G D, Lu C X, Cheng S K. 2001. Progress in evaluating the global ecosystem services[J]. Resources Science, 23(6): 5-9.]

谢高地, 张彩霞, 张昌顺, 等. 2015. 中国生态系统服务的价 值 [J]. 资源科学, 37(9): 1740-1746. [Xie G D, Zhang C $\mathrm{X}$, Zhang C S, et al. 2015. The value of ecosystem services in China[J]. Resources Science, 37(9): 1740-1746.]

徐广才, 康慕谊, 赵从举, 等. 2007. 阜康市生态敏感性评价 研究 [J]. 北京师范大学学报: 自然科学版, 43(1): 88-92. [Xu G C, Kang M Y, Zhao C J, et al. 2007. Appraisal of eco-sensitivity on Fukang City[J]. Journal of Beijing Normal University: Natural Science, 43(1): 88-92.]

许妍, 梁斌, 鲍晨光, 等. 2013. 渤海生态红线划定的指标体 系与技术方法研究 [J]. 海洋通报, 32(4): 361-367. [Xu Y, Liang B, Bao C G, et al. 2013. Research on the index system and the technical methods of ecological red line division for the Bohai Sea[J]. Marine Science Bulletin, 32(4): 361-367.]

燕守广, 林乃峰, 沈渭寿. 2014. 江苏省生态红线区域划分与 保护 [J]. 生态与农村环境学报, 30(3): 294-299. [Yan S G, Lin N F, Shen W S. 2014. Delineation and protection of ecological red lines in Jiangsu Province[J]. Journal of Ecology and Rural Environment, 30(3): 294-299.]

颜碟, 许学工, 谢正磊, 等. 2009. 北京市域生态敏感性综合 评价 [J]. 生态学报, 29(6): 3117-3125. [Yan L, Xu X G, Xie Z L, et al. 2009. Integrated assessment on ecological sensitivity for Beijing[J]. Acta Ecologica Sinica, 29(6): 
3117-3125.]

杨志峰, 徐俏, 何孟常, 等. 2002. 城市生态敏感性分析[J]. 中 国环境科学, 22(4): 360-364. [Yang Z F, Xu Q, He M C, et al. 2002. Analysis of city ecosensitivity[J]. China Environmental Science, 22(4): 360-364.]

禹莎, 王原, 李敬, 等. 2008. 北方小型工业城市生态敏感性 评价研究: 以沙河市大沙河古河道地区为例 $[\mathrm{J}]$. 复旦学 报: 自然科学版, 47(4): 501-508. [Yu S, Wang Y, Li J, et al. 2008. Appraisal of eco-sensitivity on small-sized industrial city in northern China: Set the Shahe City as an example[J]. Journal of Fudan University: Natural Science, 47(4): 501-508.]
赵同谦, 欧阳志云, 郑华, 等. 2004. 中国森林生态系统服务 功能及其价值评价 [J]. 自然资源学报, 19(4): 480-491. [Zhao T Q, Ouyang Z Y, Zheng H, et al. 2004. Forest ecosystem services and their valuation in China[J]. Journal of Natural Resources, 19(4): 480-491.]

Costanza R, D' Arge R, Groot R, et al. 1997. The value of the world' s ecosystem services and natural capital[J]. Nature, 387: 253-260.

Daily G C. 1997. Nature's services: Societal dependence on natural ecosystems[M]. Washington DC: Island Press.

Repetto R. 1992. Accounting for environmental assets[J]. Scientific American, 266(6): 94-100.

\title{
Determination of ecological red line of mountainous areas: A case study of Yihe Town in Chongqing Municipality
}

\author{
DING Yuchen', FENG Changchun ${ }^{1 *}$, WANG Liwei ${ }^{2}$ \\ (1. College of Urban and Environmental Sciences, Peking University, Beijing 100871, China; \\ 2. School of Architecture, Tsinghua University, Beijing 100084, China)
}

\begin{abstract}
Unsuitable land use is an important factor contributing to ecological problems. Determining ecological red line can coordinate the relationship between land use and the ecological environment, promote reasonable allocation of land resources, and improve regional ecological security. Research on methods to determine ecological red line has theoretical and practical values. Mountain areas have rugged terrain and dense water systems, where fragmentation of land use is often serious. They are also important areas with regard to soil and water conservation and key areas for ecological restoration and reconstruction. Taking a mountainous townYihe in Chongqing Municipality - as an example, this study used GIS tools and took into consideration ecological sensitivity and ecosystem services value to determine the rigid and flexible ecological red lines of the study area. This study chose slope, vegetation coverage, water and soil types, and erosive force of precipitation as indicators for ecological sensitivity assessment and food production, raw material production, gas regulation, climate regulation, hydrology regulation, soil retention, nutrient cycling maintenance, biodiversity, and aesthetic as indicators for ecological service assessment. The area within the rigid ecological red line is $43.90 \mathrm{~km}^{2}, 44.34 \%$ of the total area of Yihe Town; and the area within the elastic ecological read line is $29.18 \mathrm{~km}^{2}, 29.47 \%$ of the total area. Ecological red line encloses the northern and eastern mountainous area and southern area with dense water courses of the town. The ecological sensitivity and ecological services value are high is this area. The ecological red lines determined in this study identify key areas for ecological restoration and protection, and the methods and result can support policy-making for improving ecological security of the region.
\end{abstract}

Key words: mountainous areas; ecological read line; ecological sensitivity; ecosystem services value; Yihe Town of Chongqing Municipality 